\title{
Protective Effects of Cold Ringer's Solution Perfusion in Abdominal Aortic Surgery Requiring Renal Artery Clamp
}

\author{
TOMOAKI HIROSE, NORIYOSHI SAWABATA, TAKEHISA ABE, YOSHIHIRO HAYATA, \\ SYUN HIRAGA, HIROSHI NISHIKAWA and SHIGEKI TANIGUCHI \\ Department of Thoracic and Cardiovascular Surgery, \\ Nara Medical University School of Medicine, Kashihara, Japan
}

\begin{abstract}
Background/Aim: Treating abdominal aortic aneurysms (AAA) of the juxtarenal artery with renal artery clamps burdens the kidneys. We investigated the outcomes of intra-operative renal artery perfusion using the cold Ringer's solution method for renal protection. Patients and Methods: We enrolled 290 AAA patients who underwent open aortic repair. Surgical outcomes were investigated based on renal protection. Results: We evaluated 231 patients requiring infrarenal artery clamp (Group I), and 59 patients requiring perfusion in addition to the clamp (Group J). Patient demographics, acute kidney injury (AKI) incidence (Group I: $11.7 \%$ and Group J: 20.3\%), hospital mortality (Group I: $1.3 \%$ and Group J: $1.7 \%$ ), and 30-day mortality (Group I: $0.4 \%$ and Group J: 0\%) were not different between the groups. The AKI incidence was low (13\%) in cases requiring a renal artery clamp for $\geq 45 \min (n=40)$. Conclusion: Perfusion with cold Ringer's solution offers renal protection and may improve surgical outcomes.
\end{abstract}

Juxtarenal artery abdominal aortic aneurysms (AAA) reportedly account for $8-20 \%$ of AAA $(1,2)$. Because of the short neck length associated with these aneurysms $(<10 \mathrm{~mm})$, endovascular surgery alone is not indicated because of an increased risk of complications, such as endo-leak and stent migration (3). Therefore, other techniques, such as the chimney method or the fenestration method, are employed. In particular, open aortic repair is the first choice of treatment

This article is freely accessible online.

Correspondence to: Noriyoshi Sawabata, Department of Thoracic and Cardiovascular Surgery, Nara Medical University 840 Shijo-cho, Kashihara, Nara, 634-8511, Japan. Tel: +81 744223051, Fax: +81 744248040,e-mail:nsawabata@hotmail.com

Key Words: Juxtarenal abdominal aortic aneurysm, cold Ringer's solution perfusion, renal artery clamp, renal artery perfusion, renal protection. for juxtarenal AAA; however, mortality and morbidity rates are higher when this procedure is performed for juxtarenal AAA compared to the infrarenal AAA $(2,4-6)$.

Due to the need for renal artery clamps, acute kidney injury (AKI) is the most serious complication that affects the outcomes of the AAA surgery, especially in cases of juxtarenal AAA (7). In this study, we assessed the treatment outcomes of surgery using a renal artery clamp and the renal protective effects of cold Ringer's solution in patients with juxtarenal AAA.

\section{Patients and Methods}

Patient characteristics. Open aortic repair was performed in 331 AAA patients between January 2008 and December 2018 at Nara Medical University Hospital in Japan. Forty-one patients were excluded from the study for the following reasons: i) the surgery was emergency surgery, ii) the patient was undergoing dialysis, iii) the patient had an infectious aneurysm, and iv) the patient had a pseudoaneurysm. Among the remaining 290 patients, 231 required an infrarenal artery clamp (Group I), while 59 required a renal artery clamp due to juxtarenal AAA associated with renal perfusion (Group J). In all patients, drug-loaded myocardial scintigraphy or cardiac computed tomography (CT) was performed as a screening method for pre-operative ischemic heart disease.

Surgical procedure. In all cases, we approached the abdominal median incision under general anaesthesia. In Group J, there was no need to disconnect the left renal vein. The bilateral renal arteries were taped, and the abdominal aorta was detached from surrounding tissue for suprarenal aortic-cross clamping. After detachment of the abdominal aorta at the distal side, heparin sodium was administered at a dose of 80 -unit/Kg. After confirming that the activated coagulation time (ACT) exceeded 200 seconds, the bilateral renal artery was clamped, followed by clamping of the aortic aneurysm. After incision, the aortic sclerosis was promptly removed and bleeding from the lumbar artery was controlled using 3-0 polypropylene suture (Ethicon, Somerville, NJ, USA) thread. For renal artery perfusion, an $8 \mathrm{Fr}$ Atom Tube $^{\circledR}$ (Atom MEDICAL, Tokyo, Japan) was inserted into the renal artery. The temperature of the perfusion solution was at $4^{\circ} \mathrm{C}$, and was comprised of $1,000 \mathrm{ml}$ of $0.9 \%$ Ringer's solution, $125 \mathrm{mg}$ of methylprednisolone, and $63 \mathrm{ml}$ of mannitol. Perfusion was carried out for $10 \mathrm{~min}$ at a rate of $20 \mathrm{ml} / \mathrm{min}$ per kidney, before being sustained at a rate of $10 \mathrm{ml} / \mathrm{min}$. 
Table I. Kidney disease improving global outcomes (KDIGO) criteria.

\begin{tabular}{lll}
\hline Stage Definition & I. Increase in $\mathrm{SCr}$ to $\geq 0.3 \mathrm{mg} / \mathrm{dl}$ (within $48 \mathrm{~h}$ ) & \\
& II. Increase in $\mathrm{SCr}$ to 1.5 times baseline (within 7 days) & \\
& III. Urine output less than $0.5 \mathrm{ml} / \mathrm{kg} / \mathrm{h}$ for $6 \mathrm{~h}$ & \\
& $\mathrm{SCr}$ criteria & Urine output criteria \\
Stage I & $\geq 0.3 \mathrm{mg} / \mathrm{dl}$ increase & $<0.5 \mathrm{ml} / \mathrm{Kg} / \mathrm{h}$ for $6 \mathrm{~h}$ \\
& or & \\
Stage II & $1.5-1.9$ times baseline & $<0.5 \mathrm{ml} / \mathrm{Kg} / \mathrm{h}$ for $12 \mathrm{~h}$ \\
Stage III & $2.0-2.9$ times baseline & $<0.3 \mathrm{ml} / \mathrm{Kg} / \mathrm{h}$ for $24 \mathrm{~h}$ \\
& 3.0 times baseline & or \\
& or & Anuria for $\geq 12 \mathrm{~h}$ \\
& Increase in SCr to $\geq 4 \mathrm{mg} / \mathrm{dl}$ & \\
\hline
\end{tabular}

SCr: Serum creatinine.

Endpoints. The primary endpoint of this study was 30-day mortality, while the secondary endpoint was post-operative AKI. AKI was evaluated according to the Kidney Disease Improving Global Outcomes (KDIGO) (8) guidelines (Table I), excluding the diagnostic criteria with respect to the urine volume.

Statistical analyses. The measured values are expressed as mean \pm standard deviation. The $t$-test, chi-squared test, MannWhitney $U$-test, and Kaplan Meier methods were used for analyses, as appropriate. Statistical significance was defined by a $p<0.05$. All statistical analyses were performed using IBM SPSS Statistics ${ }^{\circledR}$ (IBM Tokyo, Tokyo, Japan).

Ethical considerations. This study was approved by the institutional review board of the Nara Medical University Hospital on August 26, 2019 (No. 2304). Designated consent was obtained using the "opt-out" method.

\section{Results}

The average age of patients was $71.6 \pm 7.5$ years in Group I and $71.7 \pm 6.8$ years in Group $\mathrm{J}(p=0.65)$. There was no significant difference in age, sex, maximum aneurysm diameter, comorbidities, or pre-operative renal function between the two groups (Table II). Although there were 12 cases $(20.3 \%)$ of renal artery reconstruction in Group $\mathrm{J}$, the operative time and bleeding volume did not differ significantly between the two groups (Table III).

The 30-day mortality rate in Group I was $0.4 \%$ (one case of gastrointestinal bleeding) and $0 \%$ in Group $\mathrm{J}(p=0.32)$. The rate of hospitalization death was $1.3 \%$ (3 cases: i) one case of multiple organ failure, ii) one case of gastrointestinal bleeding, and iii) one case of interstitial pneumonia) in Group I, and $1.7 \%$ (one case of ischemic heart disease) in Group $\mathrm{J}$; no significant differences were observed $(p=1.00)$ (Table III). Post-operative AKI occurred in 27 cases $(11.7 \%)$ in Group I and in 12 cases $(20.3 \%)$ in Group $\mathrm{J}(p=0.09)$. The KDIGO classification was: i) stage I in 21 cases $(77.8 \%)$, ii) Stage II
Table II. Patient characteristics.

\begin{tabular}{lccc}
\hline & $\begin{array}{c}\text { Group I } \\
(\mathrm{n}=231)\end{array}$ & $\begin{array}{c}\text { Group J } \\
(\mathrm{n}=59)\end{array}$ & $p$-Value \\
\hline Age (years) & $71.6 \pm 7.5$ & $71.7 \pm 6.8$ & 0.65 \\
Male gender (\%) & $198(86)$ & $56(95)$ & 0.07 \\
Maximum diameter & $5.2 \pm 1.1$ & $5.4 \pm 1.0$ & 0.18 \\
of aneurysm (cm) & & & \\
Current smoker $(\%)$ & $195(84)$ & $51(86)$ & 0.84 \\
Hypertension (\%) & $192(83)$ & $51(86)$ & 0.69 \\
Diabetes mellitus $(\%)$ & $28(12)$ & $10(17)$ & 0.39 \\
Dyslipidemia (\%) & $99(43)$ & $30(51)$ & 0.31 \\
COPD (\%) & $68(29)$ & $19(32)$ & 0.75 \\
Ischemic heart disease (\%) & $37(16)$ & $13(22)$ & 0.33 \\
Preoperative SCr (mg/dl) & $1.02 \pm 0.47$ & $1.09 \pm 0.41$ & 0.20 \\
Preoperative eGFR & $60.7 \pm 17.7$ & $56.7 \pm 15.4$ & 0.05 \\
(ml/min/1.73m $\left.{ }^{2}\right)$ & & & \\
Preoperative CKD stage & & & \\
$\quad$ I & 11 & 0 & 0.25 \\
II & 114 & 27 & \\
III & 89 & 29 & \\
IV & 15 & 3 & \\
V & 2 & & \\
\hline & & & \\
\hline
\end{tabular}

COPD: Chronic obstructive pulmonary disease; SCr: serum creatinine; eGFR: estimated glomerular filtration rate; CKD: chronic kidney disease.

in 3 cases $(11.1 \%)$, and iii) Stage III in 3 cases $(11,1 \%)$ in Group I. In Group J, the classification was: i) Stage I in 9 cases $(75.0 \%)$ and ii) Stage II in 3 cases $(25.0 \%)(p=0.49)$. Interestingly, at the time of discharge, 17 cases in Group I $(63.0 \%)$, and 9 cases in Group J $(75.0 \%)$ showed improved serum creatinine ( $\mathrm{SCr}$ ) levels compared to pre-operative levels (Figures 1A and B).

The three cases of KDIGO stage III in Group I are described below. The first case was a patient with preoperative chronic kidney disease (CKD) Stage IV [SCr 2.29 

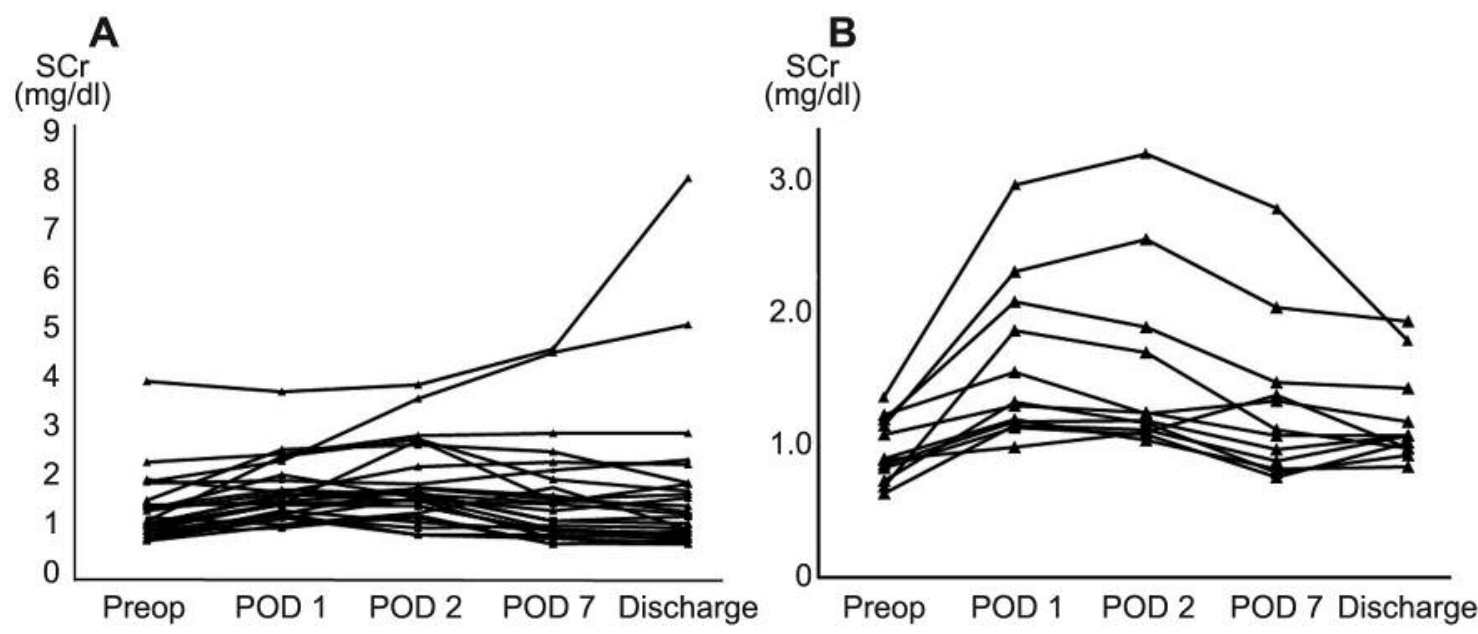

Figure 1. Changes in SCr levels for cases of AKI in (A) group I and (B) group J. SCr: Serum creatinine; AKI: acute kidney injury; POD: postoperative day.

$\mathrm{mg} / \mathrm{dl}$ and estimated glomerular filtration rate (eGFR) 22.7 $\mathrm{ml} / \mathrm{min} / 1.73 \mathrm{~m}^{2}$ ] whose post-operative $\mathrm{SCr}$ was elevated to $4.67 \mathrm{mg} / \mathrm{dl}$. Thankfully, this level returned to the preoperative level at the time of discharge because of continuous hemodiafiltration (CHDF). The second case was a patient with pre-operative CKD Stage V (SCr $3.92 \mathrm{mg} / \mathrm{dl}$ and eGFR $12.3 \mathrm{ml} / \mathrm{min} / 1.73 \mathrm{~m}^{2}$ ) who was scheduled to restart dialysis after temporary cessation for CHDF; however, the patient died on post-operative day 66 due to interstitial pneumonia. The third case was a patient with preoperative CKD Stage IV (SCr $1.9 \mathrm{mg} / \mathrm{dl}$ and eGFR 27.9 $\mathrm{ml} / \mathrm{min} / 1.73 \mathrm{~m}^{2}$ ) who started dialysis after CHDF; however, the patient died from multiple organ failure as a result of cardiac failure on post-operative day 115 .

For further analysis, Group $\mathbf{J}$ patients were divided into two groups: i) patients requiring a renal artery clamp for $\geq 45$ $\min ($ Group $\mathrm{L}, \mathrm{n}=40$ ) and ii) patients requiring a renal artery clamp for $<45 \min$ (Group S, n=19) (Table IV). There were no significant differences between the two groups with regard to the duration of intensive care unit (ICU) stay or length of post-operative hospitalization. The 30-day mortality rates were assessed because no patient died within 30 days from either group, although one patient in Group L died on post-operative day $604(2.5 \%)$. Although the preoperative $\mathrm{SCr}$ was lower in Group L compared to Group $\mathrm{S}$ $(1.15 \pm 0.06 \mathrm{mg} / \mathrm{dl}$ in Group L vs. $0.96 \pm 0.15 \mathrm{mg} / \mathrm{dl}$ in Group $\mathrm{S}, p<0.05)$, the rate of post-operative AKI was significantly smaller in Group L (13\%) compared to Group S (37\%) $(p<0.05)$. With respect to the KDIGO classification, there were four Stage I cases $(80.0 \%)$ and one Stage II case $(20.0 \%)$ in Group L, and five Stage I cases $(71.4 \%)$ and two Stage II cases $(28.6 \%)$ in Group S, but there were no Stage III cases in either group.

\section{Discussion}

AKI is a very common complication of AAA because it affects the surgical outcome and thus, the patients' survival. In general, the main risk factors for post-operative AKI associated with AAA are i) the pre-operative renal dysfunction and ii) the intra-operative renal ischemic time (9-11). During surgery for infrarenal AAA, infrarenal arterial vessel clamping causes a reduction of renal blood flow by $38 \%$ (12) and changes the blood flow distribution inside the kidney (13-17). Therefore, the use of a renal protection method is important for near-renal artery aortic aneurysms that require renal artery clamping.

Several methods, such as implementation of a shorter cutoff time, use of infusion load and diuretics to ensure urine volume, treatment of renal blood flow with continuous dopamine administration, the renal cooling method, and the renal artery perfusion method using oxygenated blood have been used to protect the kidney $(9,18,19)$. In our institution, for cases of juxtarenal AAA we perform renal protection using the cold Ringer's solution perfusion method, which has evolved mainly in the field of renal transplantation (7). In one study, the renal oxygen demand was reduced to $40 \%, 15 \%$, and less than $5 \%$ by cooling the renal substance to 30,20 , and $10^{\circ} \mathrm{C}(20)$, respectively. Although the efficacy of the cold Ringer's solution perfusion method of renal protection was reported in 1992 by Svensson et al. (21), there is some scepticism regarding the use of this method for all cases requiring interception of the renal artery. There are studies that report no use of renal perfusion (18), while others indicate prolonged renal ischemia duration in patients with renal dysfunction before surgery (7). However, we routinely perform renal protection 
Table III. Intra- and postoperative factors.

\begin{tabular}{|c|c|c|c|}
\hline & $\begin{array}{l}\text { Group I } \\
(\mathrm{n}=231)\end{array}$ & $\begin{array}{c}\text { Group J } \\
(\mathrm{n}=59)\end{array}$ & $p$-Value \\
\hline \multicolumn{4}{|l|}{ Intraoperative variables } \\
\hline $\begin{array}{l}\text { Renal artery clamp } \\
\text { (bilateral: unilateral) }\end{array}$ & - & $23: 36$ & - \\
\hline Renal artery reconstruction $(\%)$ & - & $12(20)$ & - \\
\hline Renal artery clamp time (minutes) & - & $53 \pm 18$ & - \\
\hline Total perfusate volume $(\mathrm{ml})$ & - & $525 \pm 339$ & - \\
\hline Graft type (bifurcated: tube) & $168: 64$ & $28: 31$ & $<0.05$ \\
\hline IMA reconstruction $(\%)$ & $154(67)$ & $34(58)$ & 0.22 \\
\hline Operative time $(\mathrm{min})$ & $277 \pm 60$ & $286 \pm 71$ & 0.37 \\
\hline Blood loss (ml) & $1365 \pm 980$ & $1330 \pm 1092$ & 0.56 \\
\hline \multicolumn{4}{|l|}{ Postoperative variables } \\
\hline In-hospital mortality (\%) & $\begin{array}{c}3(1.3) \\
\text { (1:pneumonia, 1:gastrointestinal } \\
\text { haemorrhage, } 1: \text { MOF) }\end{array}$ & $1(1.7)(1: \mathrm{ACS})$ & 1.00 \\
\hline 30-day mortality (\%) & $\begin{array}{c}1(0.4) \\
\text { (1: gastrointestinal haemorrhage) }\end{array}$ & $0(0)$ & 0.32 \\
\hline ICU stay (days); median (range) & $1(1-115)$ & $1(1-26)$ & 0.66 \\
\hline Postoperative hospital stay (days); median (range) & $15(10-219)$ & $16(10-600)$ & 0.44 \\
\hline $\operatorname{ACS}(\%)$ & $0(0)$ & $1(1.7)$ & 0.20 \\
\hline Pneumonia (\%) & $7(3.0)$ & $2(3.3)$ & 0.82 \\
\hline Stroke $(\%)$ & $1(0.4)$ & $1(1.7)$ & 0.46 \\
\hline Paraplegia $(\%)$ & $0(0)$ & $1(1.7)$ & 0.20 \\
\hline Lower limb reperfusion injury (\%) & $0(0)$ & $1(1.7)$ & 0.20 \\
\hline Chylous ascites $(\%)$ & $0(0)$ & $1(1.7)$ & 0.20 \\
\hline Gastrointestinal haemorrhage (\%) & $1(0.4)$ & $1(1.7)$ & 0.37 \\
\hline Ileus $(\%)$ & $4(1.7)$ & $0(0)$ & 0.59 \\
\hline Graft infection $(\%)$ & $1(0.4)$ & $0(0)$ & 1.00 \\
\hline $\mathrm{AKI}(\%)$ & $27(11.7)$ & $12(20.3)$ & 0.09 \\
\hline \multicolumn{4}{|l|}{ KDIGO Criteria } \\
\hline Stage I & 21 & 9 & \\
\hline Stage II & 3 & 3 & \\
\hline Stage III & 3 & 0 & 0.49 \\
\hline
\end{tabular}

IMA: Inferior mesenchymal artery; ICU: intensive care unit; AKI: acute kidney injury; KDIGO: kidney disease improving global outcomes; ACS: acute coronary syndrome; MOF: multiple organ failure.

with the cold Ringer's solution perfusion method in all cases of juxtarenal AAA to achieve stable renal protection and effective surgery in cases where prolonged renal artery clamping time cannot be predicted.

There are various reports regarding the composition, volume, and method of administration of fluid perfusion (2123). Using our method, we found no differences in the postoperative course, the incidence of AKI, hospital mortality, or the 30-day mortality between patients who underwent infrarenal artery interception (Group I) and patients who underwent renal artery interception due to juxtarenal type and renal perfusion (Group J). In addition, even in cases that required a long renal artery clamping duration ( $\geq 45 \mathrm{~min}$ ), the incidence of AKI was no higher compared to that of patients with shorter renal artery clamping duration. This observation indicated that surgery can be performed safely using the cold
Ringer's solution method for renal protection, even in cases requiring prolonged renal artery clamping.

There were some limitations to this study, such as its retrospective nature, the single-centre design, and the limited number of patients. Despite this, our method prevented severe AKI in all cases, and a renal protective effect was observed, even in cases requiring long-term renal artery clamping. Prospective studies with a larger number of patients from multiple centres should be conducted for a better evaluation of the cold Ringer's perfusion solution towards the surgical outcome and survival of AAA patients.

In conclusion, our surgical outcomes were good, and our findings suggest that renal perfusion with cold Ringer's solution for juxtarenal AAA that requires suprarenal aorticcross clamp is effective for renal protection. 
Table IV. Extracted analyses of juxtarenal type abdominal aortic aneurysm according to clamp time.

\begin{tabular}{|c|c|c|c|}
\hline & $\begin{array}{c}\text { Group L } \\
(\mathrm{n}=40)\end{array}$ & $\begin{array}{c}\text { Group S } \\
(\mathrm{n}=19)\end{array}$ & $p$-Value \\
\hline Age (years) & $70.7 \pm 5.7$ & $73.9 \pm 6.2$ & 0.08 \\
\hline Male sex $(\%)$ & $38(95)$ & $18(95)$ & 1.00 \\
\hline Maximum diameter of aneurysm $(\mathrm{cm})$ & $5.3 \pm 0.4$ & $5.6 \pm 0.8$ & 0.28 \\
\hline Preoperative SCr (mg/dl) & $1.15 \pm 0.06$ & $0.96 \pm 0.15$ & $<0.05$ \\
\hline Preoperative eGFR $\left(\mathrm{ml} / \mathrm{min} / 1.73 \mathrm{~m}^{2}\right)$ & $54.9 \pm 2.3$ & $60.3 \pm 11.5$ & 0.16 \\
\hline \multicolumn{4}{|l|}{ Preoperative CKD stage } \\
\hline 1 & 0 & 0 & \multirow[t]{5}{*}{0.44} \\
\hline 2 & 16 & 11 & \\
\hline 3 & 21 & 8 & \\
\hline 4 & 3 & 0 & \\
\hline 5 & 0 & 0 & \\
\hline Renal artery clamp (bilateral: unilateral) & $26: 14$ & $10: 9$ & 0.26 \\
\hline Renal artery reconstruction $(\%)$ & $12(30)$ & $0(0)$ & $<0.05$ \\
\hline Renal artery clamp time (min) & $61(45-109)$ & $38(29-44)$ & $<0.05$ \\
\hline Total perfusate volume $(\mathrm{ml})$ & $570(200-1800)$ & $385(50-888)$ & $<0.05$ \\
\hline Operative time ( $\mathrm{min})$ & $303 \pm 28$ & $249 \pm 47$ & $<0.05$ \\
\hline Blood loss (ml) & $1051(340-5830)$ & $677(160-1955)$ & $<0.05$ \\
\hline ICU stay (median) & 1 day $(1-26)$ & 1 day $(1-6)$ & 0.12 \\
\hline Postoperative hospital stay (median) (range) & 17 days (17-433) & 15 days $(10-36)$ & 0.17 \\
\hline In-hospital mortality (\%) & $1(2.5)$ & $0(0)$ & 1.00 \\
\hline 30-day mortality $(\%)$ & $0(0)$ & $0(0)$ & 1.00 \\
\hline $\mathrm{AKI}(\%)$ & $5(13)$ & $7(37)$ & $<0.05$ \\
\hline \multicolumn{4}{|l|}{ KDIGO criteria } \\
\hline Stage I & 4 & 5 & \multirow[t]{3}{*}{0.66} \\
\hline Stage II & 1 & 2 & \\
\hline Stage III & 0 & 0 & \\
\hline
\end{tabular}

SCr: Serum creatinine; eGFR: estimated glomerular filtration rate; CKD: chronic kidney disease; ICU: intensive care unit; AKI: acute kidney injury; KDIGO: kidney disease improving global outcomes.

\section{Conflicts of Interest}

The Authors have no conflicts of interest directly relevant to the content of this article.

\section{Authors' Contributions}

$\mathrm{TH}, \mathrm{TA}, \mathrm{YH}, \mathrm{SH}, \mathrm{HN}$ performed the operations. TH collected and analysed the data and wrote the manuscript. NS wrote and reviewed the manuscript. ST supervised the study.

\section{Acknowledgements}

None.

\section{References}

1 Chaikof EL, Blankensteijn JD, Harris PL, White GH, Zarins CK, Bernhard VM, Matsumura JS, May J, Veith FJ, Fillinger MF, Rutherford $\mathrm{RB}$, Kent $\mathrm{KC}$ and $\mathrm{Ad} \mathrm{Hoc}$ Committee for Standardized Reporting Practices in Vascular Surgery of The Society for Vascular Surgery/American Association for Vascular Surgery: Reporting standards for endovascular aortic aneurysm repair. J Vasc Surg 35(5): 1048-1060, 2002. PMID: 12021727. DOI: $10.1067 / \mathrm{mva} .2002 .123763$

2 West CA, Noel AA, Bower TC, Cherry KJ Jr, Gloviczki P, Sullivan TM, Kalra M, Hoskin TL and Harrington JR: Factors affecting outcomes of open surgical repair of pararenal aortic aneurysms: a 10-year experience. J Vasc Surg 43(5): 921-927; discussion 927-928, 2006. PMID: 16678684. DOI: 10.1016/ j.jvs.2006.01.018

3 AbuRahma AF, Yacoub M, Mousa AY, Abu-Halimah S, Hass SM, Kazil J, AbuRahma ZT, Srivastava M, Dean LS and Stone PA: Aortic neck anatomic features and predictors of outcomes in endovascular repair of abdominal aortic aneurysms following vs not following instructions for use. J Am Coll Surg 222(4): 579589, 2016. PMID: 26905372. DOI: 10.1016/j.jamcollsurg. 2015.12.037

4 Knott AW, Kalra M, Duncan AA, Reed NR, Bower TC, Hoskin TL, Oderich GS and Gloviczki P: Open repair of juxtarenal aortic aneurysms (JAA) remains a safe option in the era of fenestrated endografts. J Vasc Surg 47(4): 695-701, 2008. PMID: 18272317. DOI: $10.1016 /$ j.jvs.2007.12.007

5 Tallarita T, Sobreira ML and Oderich GS: Results of open pararenal abdominal aortic repair: Tabular review of the literature. Ann Vasc Surg 25(1): 143-149, 2011. PMID: 21172590. DOI: $10.1016 /$ j.avsg.2010.10.005 
6 Kabbani LS, West CA, Viau D, Nypaver TJ, Weaver MR, Barth $\mathrm{C}$, Lin JC and Shepared AD: Survival after repair of pararenal and paravisceral abdominal aortic aneurysms. J Vasc Surg 59(6): 1488-1494, 2014. PMID: 24709440. DOI: 10.1016/j.jvs. 2014.01.008

7 Allen BT, Anderson CB, Rubin BG, Flye MW, Baumann DS and Sicard GA: Preservation of renal function in juxtarenal and suprarenal abdominal aortic aneurysm repair. J Vasc Surg 17(5): 948-958; discussion 958-959, 1993. PMID: 8487364. DOI: $10.1067 /$ mva.1993.46197

8 Kellum JA, Lamiere N, Aspelin P, Barsoum RS, Burdmann EA, Goldstein SL, Herzog CA, Joannidis M, Kribben A, Levey AS, MacLeod AM, Mehta RL, Murray PT, Naicker S, Opal SM, Schaefer F, Schetz M and Uchino S: Kidney Disease: Improving Global Outcomes (KDIGO) acute kidney injury work group. KDIGO clinical practice guidelines for acute kidney injury. Kidney Int 2(1): 1-138, 2012. DOI: 10.1038/kisup.2012.1

9 Jean-Claude JM, Reilly LM, Stoney RJ and Messina LM: Pararenal aortic aneurysm: the future of open aortic aneurysm repair. J Vasc Surg 29(5): 902-912, 1999. PMID: 10231642. DOI: $10.1016 / \mathrm{s} 0741-5214(99) 70218-1$

10 Crawford ES, Beckett WC and Greer MS: Juxtarenal infrarenal abdominal aortic aneurysm. Special diagnostic and therapeutic considerations. Ann Surg 203(6): 661-670, 1986. PMID: 3521511. DOI: $10.1097 / 00000658-198606000-00011$

11 Wahlberg E, Dimuzio PJ and Stoney RJ: Aortic clamping during elective operations for infrarenal disease: The influence of clamping time on renal function. J Vasc Surg 36(1): 13-18, 2002. PMID: 12096250. DOI: 10.1067/mva.2002.123679.

12 Gamulin Z, Forster A, Morel D, Simonet F, Aymon E and Favre $\mathrm{H}$ : Effect of infrarenal aortic cross-clamping on renal hemodynamics in humans. Anesthesiology 61(4): 394-399, 1984. PMID: 6486501. DOI: 10.1097/00000542-198410000-00006

13 Abbott WM and Austen WG: The reversal of renal cortical ischemia during aortic occlusion by mannitol. J Surg Res 16(5): 482-489, 1974. PMID: 4831725. DOI: 10.1016/0022-4804(74) 90073-0

14 McNay JL and Abe Y: Pressure-dependent heterogeneity of renal cortical blood flow in dogs. Circ Res 27(4): 571-587, 1970. PMID: 4918732. DOI: 10.1161/01.res.27.4.571

15 Stein JH, Boonjarern S, Wilson CV and Ferris TF: Alterations in intrarenal blood flow distribution. Methods of measurement and relationship to sodium balance. Circ Res 32(Suppl 1): 6172, 1973. PMID: 4576386.
16 Shanser JD, Korobkin M, Seidlitz L, Carlson EL and Shames DM: Hazards in interpretation of xenon washout studies of the canine kidney. Radiology 111(2): 461-463, 1974. PMID: 4818988. DOI: 10.1148/111.2.461

17 Slotkoff LM, Logan A, Jose P, D'Avella J and Eisner GM: Microsphere measurement of intrarenal circulation of the dog. Circ Res 28(2): 158-166, 1971. PMID: 4927075. DOI: 10.1161/01.res.28.2.158

18 Kudo FA, Nishibe T, Miyazaki K, Murashita T, Yasuda K, Ando $\mathrm{M}$ and Nishibe $\mathrm{M}$ : Postoperative renal function after elective abdominal aortic aneurysm repair requiring suprarenal aortic cross-clamping. Surg Today 34(12): 1010-1013, 2004. PMID: 15580383. DOI: $10.1007 / \mathrm{s} 00595-004-2871-9$

19 Sasaki T, Ohsawa S, Ogawa M, Mukaida M, Nakajima T, Komoda K, Tachieda R, Niinuma $\mathrm{H}$ and Kawazoe $\mathrm{K}$ : Postoperative renal function after an abdominal aortic repair requiring a suprarenal aortic cross-clamp. Surg Today 30(1): 3336, 2000. PMID: 10648080. DOI: 10.1007/PL00010043

20 Semb G, Krog J and Johansen K: Renal metabolism and blood flow during local hypothermia, studied by means of renal perfusion in situ. Acta Chir Scand Suppl 253: 196-202, 1960. PMID: 14444813.

21 Svensson LG, Crawford ES, Hess KR, Coselli JS and Safi HJ: Thoracoabdominal aortic aneurysms associated with celiac, superior mesenteric, and renal artery occlusive disease: methods and analysis of results in 271 patients. J Vasc Surg 16(3): 378389; discussion 389-390, 1992. PMID: 1522640.

22 Stoney RJ, Skiöldebrand CG, Qvafordt PG, Reilly LM and Ehrenfeld WK: Juxtarenal aortic atherosclerosis. Surgical experience and functional result. Ann Surg 200(3): 345-354, 1984. PMID: 6465985. DOI: 10.1097/00000658-19840900000012

23 Inoue T, Oka H and Saga T: Renal preservation in low ectopic right renal artery reconstruction during abdominal aortic aneurysm repair: report of a case. Surg Today 33(2): 117-119, 2003. PMID: 12616373. DOI: 10.1007/s005950300025

Received October 21, 2019

Revised November 24, 2019

Accepted November 26, 2019 